\title{
Reproductive performance and herd exit dynamics of lactating dairy cows managed for first service with the Presynch-Ovsynch or Double- Ovsynch protocol and different duration of the voluntary waiting period
}

\author{
M. L. Stangaferro, R. Wijma, M. Masello, and J. O. Giordano ${ }^{1}$ \\ Department of Animal Science, Cornell University, Ithaca, NY 14853
}

\begin{abstract}
The objective of this experiment was to evaluate the reproductive performance and herd exit dynamics of dairy cows managed for first service with programs varying in method of submission for insemination and voluntary waiting period (VWP) duration. Holstein cows from a commercial farm in New York were randomly allocated to receive timed artificial insemination (TAI) after the Double-Ovsynch protocol $(\mathrm{GnRH}, 7 \mathrm{~d}$ later $\mathrm{PGF}_{2 \alpha}, 3$ d later $\mathrm{GnRH}, 7 \mathrm{~d}$ later $\mathrm{GnRH}, 7 \mathrm{~d}$ later $\mathrm{PGF}_{2 \alpha}, 56 \mathrm{~h}$ later $\mathrm{GnRH}$, and 16 to $18 \mathrm{~h}$ later TAI) at $60 \pm 3 \mathrm{~d}$ in milk (DIM) $(\mathrm{DO} 60=458)$, TAI after Double-Ovsynch at $88 \pm 3$ DIM $($ DO88 $=462)$, or a combination of AI at detected estrus (starting at $50 \pm 3 \mathrm{~d}$ in milk) and TAI with the Presynch-Ovsynch protocol $\left(\mathrm{PGF}_{2 \alpha}, 14 \mathrm{~d}\right.$ later $\mathrm{PGF}_{2 \alpha}, 12$ d later $\mathrm{GnRH}$, $7 \mathrm{~d}$ later $\mathrm{PGF}_{2 \alpha}, 56 \mathrm{~h}$ later $\mathrm{GnRH}$, and 16 to $18 \mathrm{~h}$ later TAI; PSOv $=450$ ). Subsequent artificial insemination (AI) services were conducted at detected estrus or the Ovsynch protocol (32 \pm 3 d after AI GnRH, 7 d later $\mathrm{PGF}_{2 \alpha}, 56 \mathrm{~h}$ later $\mathrm{GnRH}$, and 16 to $18 \mathrm{~h}$ later TAI) for cows not reinseminated at detected estrus. In a subgroup of cows, cyclicity (based on progesterone concentration), uterine health (vaginal discharge and uterine cytology), and BCS were evaluated at baseline (DO60 and DO $88=33 \pm 3$ DIM; PSOv $=34 \pm 3$ DIM), beginning of the synchronization protocol $(\mathrm{DO} 60=33$ \pm 3 DIM; DO $88=61 \pm 3$ DIM; PSOv $=34 \pm 3$ DIM $)$, and within -5 (PSOv) or $-10 \mathrm{~d}$ (DO) of the VWP end $(\mathrm{DO} 60=50 \pm 3$ DIM; DO88 $=78 \pm 3$ DIM; PSOv $=45 \pm 3$ DIM). Effects of treatments were assessed with multivariable statistical methods relevant for each outcome variable. Cows in the DO88 treatment had delayed time to pregnancy during lactation (DO60 vs. DO88 hazard ratio $=1.53,95 \%$ confidence interval $=1.32$ to 1.78 ; PSOv vs. DO88 hazard ratio $=1.37$,
\end{abstract}

Received June 30, 2017.

Accepted October 27, 2017.

${ }^{1}$ Corresponding author: jog25@cornell.edu
$95 \%$ confidence interval $=1.19$ to 1.61 ) and, within multiparous cows, the DO88 and PSOv treatments had greater risk of leaving the herd than cows in the DO60 treatment (DO88 vs. DO60 hazard ratio $=1.49,95 \%$ confidence interval $=1.11$ to $2.00 ;$ PSOv vs. DO60 hazard ratio $=1.39,95 \%$ confidence interval $=1.03$ to 1.85). Cows in the DO88 treatment had improved uterine health, greater BCS, and reduced incidence of anovulation than cows in DO60 and PSOv; however, overall pregnancy per AI $39 \pm 3$ d after AI was similar for the 3 treatment groups. In summary, reproductive management strategies that led to similar average DIM to the first service $(\sim 60 \mathrm{~d})$ through a combination of AI at estrus with TAI (PSOv) or all TAI (DO60) resulted in reduced time to pregnancy after calving when compared with an all TAI program (DO88) with a VWP of $88 \mathrm{~d}$. Within the multiparous cow group, those that received all TAI with a VWP duration of $60 \mathrm{~d}$ were less likely to leave the herd than cows in the other treatments.

Key words: voluntary waiting period, Double-Ovsynch, Presynch-Ovsynch, reproductive performance, dairy cow

\section{INTRODUCTION}

Reproductive management strategies incorporating synchronization of estrus and ovulation for first service have been widely adopted by the dairy industry in recent years (Caraviello et al., 2006; Ferguson and Skidmore, 2013; Wiltbank and Pursley, 2014). These strategies reduce the number of and variation for days to the first service (Pursley et al., 1997; Miller et al., 2007). More recently, fertility programs were developed to maximize pregnancy per AI $(\mathbf{P} / \mathbf{A I})$ by improving synchrony of ovulation and optimizing the endocrine environment before timed AI (TAI; Moreira et al., 2001; Bello et al., 2006; Souza et al., 2008). Thus, incorporating synchronization of estrus and ovulation protocols for first service allows better control of the timing of pregnancy during lactation through immediate insemination after the end of the voluntary waiting 
period (VWP; Chebel and Santos, 2010; Machado et al., 2017), similar or greater $\mathrm{P} / \mathrm{AI}$ than inseminations at detected estrus (Chebel and Santos, 2010; Fricke et al., 2014; Santos et al., 2017), or both.

Two of the most widely used strategies to submit lactating dairy cows for first service include (1) combining insemination after detection of estrus and TAI and (2) submission of all cows for TAI (Caraviello et al., 2006; Ferguson and Skidmore, 2013; Scott, 2016). Among combined strategies, a common approach consists of synchronizing estrus so that a substantial proportion of cows receive AI immediately after the end of the VWP. Thereafter, cows not detected in estrus receive TAI through synchronization of ovulation. Indeed, $\mathrm{PGF}_{2 \alpha^{-}}$ based presynchronization protocols, such as PresynchOvsynch, are used by many dairy farms because up to $\sim 50$ to $70 \%$ of cows may be inseminated at estrus after the $\mathrm{PGF}_{2 \alpha}$ treatments of the protocol (Chebel et al., 2006; Fricke et al., 2014; Giordano et al., 2016). This strategy drastically reduces the number of cows submitted to TAI, and thereby the number of hormonal treatments and associated labor. A caveat of combining AI at estrus with TAI through the Presynch-Ovsynch protocol is the wide range of DIM to the first service and the fact that $\mathrm{P} / \mathrm{AI}$ may be reduced as compared with using only TAI (Gumen et al., 2012; Fricke et al., 2014; Borchardt et al., 2016). In contrast, GnRH-based presynchronization protocols, such as Double-Ovsynch, may be more suitable for all TAI. These protocols do not promote estrus expression, but through resolution of anovulation in most cows (Souza et al., 2008; Herlihy et al., 2012; Ayres et al., 2013) and improved synchrony of ovulation increase first-service $\mathrm{P} / \mathrm{AI}$ when compared with $\mathrm{PGF}_{2 \alpha}$-based presynchronization protocols, such as Presynch-Ovsynch, especially in primiparous cows (Souza et al., 2008; Herlihy et al., 2012; Borchardt et al., 2017). Thus, for farms aiming to reduce variation for days to the first service while maximizing $\mathrm{P} / \mathrm{AI}$, a GnRH-based protocol such as Double-Ovsynch may be superior to a combined program using a $\mathrm{PGF}_{2 \alpha}$-based protocol such as Presynch-Ovsynch.

Several experiments compared $\mathrm{P} / \mathrm{AI}$ and wholelactation reproductive performance after submission to the first service with combined or all TAI programs (Chebel and Santos, 2010; Fricke et al., 2014; Machado et al., 2017). Although differences in P/AI were reported, time to pregnancy during lactation was similar for both strategies. In all cases, however, cows received all TAI after synchronization with the Presynch-Ovsynch protocol, which does not maximize $\mathrm{P} / \mathrm{AI}$ to the first service, in particular for primiparous cows (Souza et al., 2008; Herlihy et al., 2012; Borchardt et al., 2017). Therefore, it remains to be determined whether using a GnRH-based protocol, such as Double-Ovsynch, which is known to lead to greater first-service $\mathrm{P} / \mathrm{AI}$ than $\mathrm{PGF}_{2 \alpha}$-based protocols, results in better reproductive performance than a combined approach (i.e., at estrus and TAI) to submit cows to first service such as the Presynch-Ovsynch protocol.

Another important aspect of first-service management strategies that may affect time to pregnancy during lactation is duration of the VWP. Extra days of VWP may help reduce the proportion of cows with uterine disease around the time of insemination (Gautam et al., 2009; Sheldon et al., 2009; LeBlanc, 2014), allow more cows to resume hormone secretion patterns that promote ovulation and resumption of ovarian cyclicity (Butler, 2003; Kawashima et al., 2012; Cheong et al., 2016), and provide more time for cows to recover BCS, all of which have been strongly associated with positive first-service outcomes (Souza et al., 2008; Herlihy et al., 2012; Carvalho et al., 2014a). The potential benefits of extending the VWP on first-service P/AI may be more easily realized with all TAI programs using GnRH-based synchronization of ovulation protocols because of the narrow range of DIM to the first service and the potential to obtain $\mathrm{P} / \mathrm{AI}$ in the 45 to $55 \%$ range (Souza et al., 2008; Giordano et al., 2013; Carvalho et al., 2014b). Nevertheless, it is unknown if the expected increase in $\mathrm{P} / \mathrm{AI}$ to the first service obtained by extending the VWP would compensate for the additional pregnancies generated earlier using programs with shorter VWP.

Thus, we hypothesized that cows managed with shorter VWP and 2 different methods of submission for first service (i.e., combination of insemination at estrus and TAI or all TAI) would have reduced time to pregnancy after calving in spite of reduced $\mathrm{P} / \mathrm{AI}$ to the first service. We expected that earlier reinsemination of cows with shorter VWP would compensate for the increment in $\mathrm{P} / \mathrm{AI}$ in cows with longer VWP. Therefore, we conducted an experiment with the main objective of investigating the effect of submitting lactating dairy cows for first service with 3 different management strategies on time to pregnancy and herd exit dynamics. Cows received first service after detection of estrus or TAI during the Presynch-Ovsynch protocol with VWP of $50 \pm 3$ DIM, or received TAI after the Double-Ovsynch protocol with VWP of $60 \pm 3$ or 88 \pm 3 DIM. Secondary objectives included determination of cyclicity status, uterine health, and BCS before first service.

\section{MATERIALS AND METHODS}

All procedures performed with cows were approved by the Animal Care and Use Committee of Cornell University. 


\section{Animals and Management}

Lactating Holstein cows ( $\mathrm{n}=1,370)$ from a commercial farm in New York State (Cayuga County) were enrolled in this experiment from March to December 2014. Cows were housed in freestall barns with 6 rows of stalls, concrete flooring, fans and sprinklers in the feedline, and self-locking headgates in the feedline. Stall surfaces were covered with either deep sand bedding or mattresses covered with sawdust. Cows assigned to the 3 management strategies evaluated were commingled during the experiment. Cows were milked thrice daily at $\sim 8$-h intervals and received recombinant bST (Sometribove zinc, Posilac, Elanco Animal Health, Indianapolis, IN) following a 10- and 11-d schedule beginning at 110 DIM until dry off. During the experiment, average number of milking cows in the herd was 1,417 with milk production of $40 \mathrm{~kg} / \mathrm{d}$ (data obtained with the ECON $\backslash$ ID command in DairyComp305, ValleyAg Software, Tulare, CA).

\section{Experimental Design}

The experiment followed a complete randomized block design with parity (i.e., primiparous vs. multiparous) as the blocking factor. At $7 \pm 3$ DIM, cows were blocked by parity and stratified based on milk production in the previous lactation (multiparous cows only). Thereafter, cows were randomly allocated to receive first-service TAI after the Double-Ovsynch protocol (DO; GnRH,7 d later $\mathrm{PGF}_{2 \alpha}, 3$ d later GnRH, 7 d later GnRH, 7 d later $\mathrm{PGF}_{2 \alpha}, 56$ h later $\mathrm{GnRH}$, and 16 to 18 $\mathrm{h}$ later TAI) at $60 \pm 3 \mathrm{DIM}(\mathbf{D O 6 0}=458)$, TAI after DO at $88 \pm 3$ DIM $(\mathbf{D O 8 8}=462)$, or a combination of insemination after detected estrus and TAI with the Presynch-Ovsynch protocol $\left(\mathbf{P S O v}=450 ; \mathrm{PGF}_{2 \alpha}, 14\right.$ d later $\mathrm{PGF}_{2 \alpha}, 12 \mathrm{~d}$ later $\mathrm{GnRH}, 7 \mathrm{~d}$ later $\mathrm{PGF}_{2 \alpha}, 56$ $\mathrm{h}$ later GnRH, and 16 to $18 \mathrm{~h}$ later TAI). Cows in the PSOv treatment received AI at detected estrus (EDAI) after the second $\mathrm{PGF}_{2 \alpha}$ treatment given at $50 \pm 3$ DIM. Cows not inseminated at estrus that completed the Presynch-Ovsynch protocol received TAI at $72 \pm$ 3 DIM (Figure 1). Cows failing to conceive to an insemination were reinseminated after detection of estrus through a combination of physical activity monitoring using neck-mounted physical activity-monitoring tags (DeLaval Activity Meter System, DeLaval International AB, Tumba, Sweden) and visual observation by farm personnel. Every morning, the dairy herd-management software (DairyComp305) generated a list of cows for insemination based on estrus alerts generated by the activity monitoring system. Cows not reinseminated at estrus and confirmed nonpregnant $39 \pm 3 \mathrm{~d}$ after a previous AI service received TAI after resynchronization of ovulation with the Ovsynch protocol (GnRH, 7 d later $\mathrm{PGF}_{2 \alpha}, 56 \mathrm{~h}$ later GnRH, 16 to $18 \mathrm{~h}$ later TAI) initiated $32 \pm 3$ d after AI (7 d before nonpregnancy diagnosis).

For all synchronization of ovulation protocols, GnRH treatments consisted of $100 \mu \mathrm{g}$ of Gonadorelin diacetate tetrahydrate given i.m. (Fertagyl, Merck Animal Health, Madison, $\mathrm{NJ}$ ), whereas $\mathrm{PGF}_{2 \alpha}$ treatments consisted of $500 \mu \mathrm{g}$ of Cloprostenol sodium given i.m. (Estrumate, Merck Animal Health). Cows that were sold, died, or were classified as do not breed by farm personnel before 30 DIM were excluded from the experiment. Cows that received first AI outside the DIM range specified for their respective treatment were also excluded. A total of 68 cows (DO60, $\mathrm{n}=22$; DO88, $\mathrm{n}=33$; PSOV, $\mathrm{n}=$ 13) were excluded. Therefore, the total number of cows with data available after 30 DIM for each treatment was 436 for DO60, 429 for DO88, and 437 for PSOv.

\section{Blood Sampling and Determination of Circulating Progesterone Concentrations}

Blood samples were collected from a subgroup of cows $(\mathrm{n}=463 ; \mathrm{DO} 60=165, \mathrm{DO} 88=142$, and PSOv $=156$ ) by puncture of the coccygeal vein or artery using 8-mL heparinized evacuated tubes (BD Vacutainer, Franklin Lakes, NJ). Samples were immediately placed into crushed ice until transport to the laboratory. Samples were centrifuged at $2,000 \times g$ for $20 \mathrm{~min}$ at $4^{\circ} \mathrm{C}$ in a refrigerated centrifuge. Plasma was harvested, transferred to 3 storage tubes, and stored at $-20^{\circ} \mathrm{C}$ until assayed.

The sampling schedule is presented in Figure 1. Samples were collected at different time points to represent the following stages for each treatment: baseline (26 \pm 3 and $33 \pm 3$ DIM for DO60 and DO88, and $27 \pm 3$ and $34 \pm 3$ DIM for PSOv), beginning of the synchronization protocol $(26 \pm 3$ and $33 \pm 3$ DIM for DO60; $54 \pm$ 3 and $61 \pm 3$ DIM for DO88; $27 \pm 3$ and $34 \pm 3$ DIM for PSOv), and, finally, within -5 (i.e., for PresynchOvsynch) or $-10 \mathrm{~d}$ (i.e., for Double-Ovsynch) of the VWP end (50 \pm 3 DIM DO60; $78 \pm 3$ DIM for DO88; $45 \pm 3$ DIM for PSOv). At baseline and the beginning of the synchronization protocols, cows were classified as cyclic if at least 1 of the samples collected $7 \mathrm{~d}$ apart had a progesterone $(\mathbf{P} 4)$ concentration $\geq 1 \mathrm{ng} / \mathrm{mL}$. Minor adjustments to sampling time points (e.g., baseline at 27 and 34 DIM instead of 26 and 33 DIM) were necessary for the PSOv treatment because of the different days of the week cows received hormonal treatments.

Plasma P4 concentrations were determined in duplicate using a commercial solid-phase, no-extraction RIA (ImmuChem Coated Tube, MP Biomedicals, Costa Mesa, CA $)$. Control samples with low $(0.3 \mathrm{ng} / \mathrm{mL})$ and high $(5.8 \mathrm{ng} / \mathrm{mL})$ P4 concentrations were included at 
the beginning and end of each assay ( $\mathrm{n}=4$ assays) to assess precision. Average detection limit for all the assays was $0.1 \mathrm{ng} / \mathrm{mL}$. Average intra-assay coefficient of variation $(\mathbf{C V})$ for the low-concentration sample was $11.4 \%$, whereas the interassay CV was $19.9 \%$. For the high-concentration sample, the average intra-assay CV was $5.6 \%$, whereas the interassay CV was $7.9 \%$. The presence of a functional corpus luteum was defined as circulating $\mathrm{P} 4$ concentration $\geq 1 \mathrm{ng} / \mathrm{mL}$.

\section{BCS}

Body condition score was recorded every time a blood sample was collected. A scale of 1 (emaciated) to 5 (fat) with increments of 0.25 was used (Edmonson et al., 1989). Data for BCS were dichotomized using a threshold of 2.75 units (high $\geq 2.75$, low $<2.75$ ).

\section{Uterine Health Examinations}

Uterine health status was determined by evaluation of vaginal discharge and uterine cytology samples at baseline (DO60 and DO88 $=33 \pm 3$ DIM; PSOv $=34$ \pm 3 DIM), beginning of the synchronization protocol $(\mathrm{DO} 60=33 \pm 3$ DIM; DO88 $=61 \pm 3$ DIM; PSOv
$=34 \pm 3$ DIM), and within -5 (i.e., for PresynchOvsynch) or -10 d (i.e., for Double-Ovsynch) of the VWP end $(\mathrm{DO} 60=50 \pm 3$ DIM; DO88 $=78 \pm 3$ $\mathrm{DIM}$; PSOv $=45 \pm 3 \mathrm{DIM})$. Discharge present in the vagina was exteriorized using the Metricheck device (Simcro, Hamilton, New Zealand) and classified according to McDougall et al. (2007) on a scale of 0 to 5 $(0=$ no discharge, $1=$ clear mucus, $2=$ clear mucus with flecks of pus, $3=$ mucopurulent but $<50 \%$ pus, 4 $=$ mucopurulent with $>50 \%$ pus, and $5=$ foul-smelling discharge). For subsequent analysis, vaginal discharge score was dichotomized, defining purulent vaginal discharge (PVD) as a Metricheck score $>2$ (LeBlanc et al., 2002).

The percentage of PMN present in uterine cytology samples collected through the Cytobrush technique was determined as described by Madoz et al. (2013). A stainless steel gun attached to a sterile brush (Medscand Cytobrush Plus GT, CooperSurgical Inc., Trumbull, CT) was used to collect samples. Once collected, samples were air-dried and stained using the Dip Quick kit (Jorgensen Laboratories Inc., Loveland, CO). All slides were evaluated at $400 \times$ magnification by a single observer. Percentage PMN was calculated by averaging 2 counts of 100 cells each from 2 different locations on

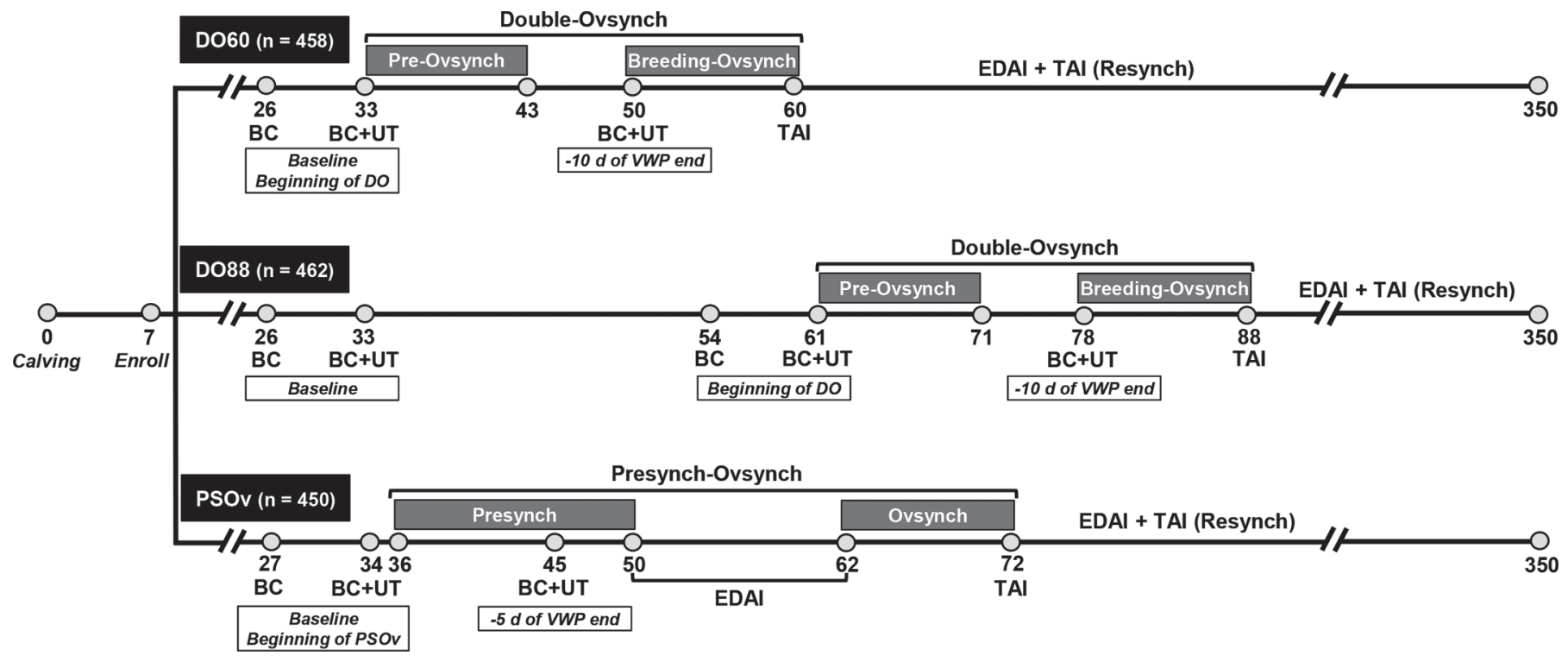

Figure 1. Schematic representation of experimental procedures. Cows were randomly allocated to receive first-service timed AI (TAI) after the Double-Ovsynch protocol (DO) at $60 \pm 3$ DIM (DO60 =458), TAI after DO at $88 \pm 3$ DIM (DO88 = 462), or a combination of insemination after detected estrus and TAI with the Presynch-Ovsynch protocol (PSOv $=450)$. Cows in the PSOv treatment received AI at detected estrus (EDAI) after the second $\mathrm{PGF}_{2 \alpha}$ treatment given at $50 \pm 3$ DIM or TAI at $72 \pm 3$ DIM. Subsequent AI services occurred through EDAI or TAI after resynchronization of ovulation with the Ovsynch protocol (Resynch). Cyclicity (progesterone concentration in circulation), uterine health (UT; vaginal discharge and uterine cytology), and BCS were determined at baseline (DO60 and DO88 $=33 \pm 3$ DIM; PSOv $=34 \pm 3$ DIM), beginning of the synchronization protocol (DO60 $=33 \pm 3$ DIM; DO88 $=61 \pm 3$ DIM; PSOv $=34 \pm 3$ DIM), and -5 (i.e., for PSOv) or $-10 \mathrm{~d}$ (i.e., for DO) of the voluntary waiting period (VWP) end (DO60 $=50 \pm 3$ DIM; DO $88=78 \pm 3$ DIM; PSOv $=45 \pm 3$ DIM). For determination of cyclicity status at baseline and beginning of DO, samples were collected $7 \mathrm{~d}$ apart and cows were classified as cyclic if at least 1 of the samples had a $\mathrm{P} 4$ concentration $\geq 1 \mathrm{ng} / \mathrm{mL}$. BC $=$ blood collection. 
each slide. If the difference between the 2 counts was greater than 10 percentage points, a third count was performed. The final percentage was calculated as the average of the 3 counts.

\section{Pregnancy Testing}

Pregnancy testing was conducted by transrectal ultrasonography (Ibex Pro, Loveland, CO) of the reproductive tract $39 \pm 3 \mathrm{~d}$ after AI. Reconfirmation of pregnancy after the initial examination was performed by transrectal ultrasonography $95 \pm 3 \mathrm{~d}$ after AI. A cow was considered to have undergone pregnancy loss after the initial examination if found nonpregnant at reconfirmation or if reinseminated at estrus before reconfirmation of pregnancy.

\section{Daily Milk Production}

Monthly milk test data retrieved from the dairy management software (DairyComp305) was used to calculate daily milk production for every cow in the study using the MilkBot model (Ehrlich, 2011). This model estimated 4 parameters (scale, ramp, offset, and decay) that, in combination with DIM, allowed prediction of daily milk production. Milk production tertiles (low, medium, and high) were estimated for primiparous and multiparous cows enrolled in the experiment using accumulated milk production up to 30 DIM (MK30). Thresholds for MK30 tertiles were established for primiparous (low $\leq 747 \mathrm{~kg}$; medium $=748$ to $866 \mathrm{~kg}$; high $\geq 867 \mathrm{~kg}$ ) and multiparous cows (low $\leq 1,061 \mathrm{~kg}$; medium $=1,062$ to $1,217 \mathrm{~kg}$; and high $\geq 1,218 \mathrm{~kg}$ ).

\section{Statistical Analysis}

Sample size estimations were conducted using the sample size calculation option of WinPepi version 11.54 (Abramson, 2011). A total of 374 cows per group were needed to detect a hazard ratio for pregnancy of 1.25 , assuming a proportion of nonpregnant cows (probability of survival) at 350 DIM of $15 \%$, probability of type I error rate of $5 \%$, and a power of $80 \%$. Additional cows $(\sim 20 \%)$ were enrolled in the experiment to compensate for cow losses beyond the control of the researchers.

Statistical analyses for binary outcomes [i.e., P/AI, pregnancy loss, proportion of cows AI at estrus, proportion of cows sold, died, or left the herd (sold plus dead), proportion of cows with $\mathrm{P} 4 \geq 1 \mathrm{ng} / \mathrm{mL}, \mathrm{PVD}$, and BCS $\geq 2.75$ ] were performed using logistic regression with the GLIMMIX procedure of SAS (version 9.4, SAS Institute Inc., Cary, NC). For quantitative outcomes (i.e., interservice interval), ANOVA was performed with the
MIXED procedure of SAS. Assumptions of normality of residuals, linear relationship, and homoscedasticity of variance were tested by evaluating the normal probability plot (normal Q-Q plot) and plotting residuals versus predicted values. Poisson regression with the GENMOD procedure of SAS was used to analyze count data (i.e., PMN number and total number of inseminations). Goodness of fit of all models was evaluated with the Pearson Chi-Square test. Cox's proportional hazards regression with the PHREG procedure of SAS was used for the analysis of time to event data (i.e., time to pregnancy and herd exit). For time-to-pregnancy analysis, a cow was considered pregnant only if pregnancy was maintained up to $150 \mathrm{~d}$ of gestation. Cows were right censored if they left the herd due to sale or death before 350 DIM and if not pregnant at 350 DIM for the analysis of time to pregnancy and time to herd exit after calving. Likewise, cows were right censored if they left the herd due to sale or death or were not pregnant by $250 \mathrm{~d}$ after the end of the VWP for the analysis of time to pregnancy after the end of the VWP. The proportional hazard assumption for time to event data analysis was evaluated by graphical examination of the $\log [-\log$ (survival probability) $]$ function obtained from the PROC LIFETEST of SAS. According to this analysis, the assumption of proportional hazards was met for all models. Kaplan-Meier survival curves generated with the survival analysis option of MedCalc (version 17.2; MedCalc Software bvba, Ostend, Belgium) were used to illustrate time to pregnancy and herd exit. The proportion of cows pregnant at 91 DIM, when all cows received at least 1 insemination (i.e., end of DIM range to the first service in the DO88 treatment), was calculated including all cows enrolled in the study by 30 DIM (similar to survival analysis for time to pregnancy after calving) and analyzed using logistic regression with the GLIMMIX procedure of SAS.

Treatment (DO60, DO88, and PSOv), parity (primiparous vs. multiparous), and the treatment by parity interaction were offered as explanatory variables to all models. For outcomes related to first AI, the effect of MK30 (low, medium, and high), season of insemination (cold: September 21-June 20; warm: June 21-September 20), treatment by MK30 interaction, and treatment by season interaction were also offered to the models. Season of first insemination was not included in the models to evaluate cyclicity status, uterine health, BCS, and time to event outcomes. The final model for each outcome of interest was selected by backward elimination of explanatory variables with $P>0.10$ and determination of the lowest value for the Aikaike information criterion. Treatment and parity were forced in all models. When appropriate, the least significant dif- 
ference (LSD) post hoc mean separation test was used to determine differences between least squares means (LSM).

All proportions reported are LSM generated using the LSMEANS option of PROC GLIMMIX of SAS, whereas quantitative outcomes were reported as LSM \pm standard error of the mean. All explanatory variables and their interactions were considered significant if $P$ $\leq 0.05$, whereas $P$-values $>0.05$ and $\leq 0.10$ were considered a tendency.

\section{RESULTS}

\section{Time to Pregnancy After Calving and After the End of the VWP}

The hazard of pregnancy after calving was affected by treatment $(P<0.01)$, whereby it was greater for the DO60 than DO88 treatment [hazard ratio $(\mathbf{H R})=$ $1.53,95 \% \mathrm{CI}=1.32-1.78$; Figure 2), and for the PSOv than DO88 treatment $(\mathrm{HR}=1.37,95 \% \mathrm{CI}=1.19-1.61$; Figure 2). No differences were observed between the DO60 and PSOv treatments $(\mathrm{HR}=1.12,95 \% \mathrm{CI}=$ $0.96-1.30)$. Median and mean days to pregnancy were 90 and 123 for DO60, 116 and 150 for DO88, and 96 and 126 for PSOv. The proportion of cows pregnant at 91 DIM, when all cows received at least 1 service, was also greater $(P<0.01)$ for DO60 $(51.0 \%$; $\mathrm{n}=436)$ and PSOv (48.3\%; $\mathrm{n}=437)$ than for DO88 (39.1\%; $\mathrm{n}=$ 429). Primiparous cows had greater $(P<0.01)$ hazard of pregnancy than multiparous cows $(\mathrm{HR}=1.52,95 \%$ $\mathrm{CI}=1.33-1.72$ ). Median and mean days to pregnancy were 89 and 116 for primiparous cows and 112 and 146 for multiparous cows, respectively. The hazard of pregnancy was not affected by MK30 $(P=0.18)$, and we found no treatment by parity $(P=0.92)$ or treatment by MK30 interaction $(P=0.58)$. At 350 DIM, the proportion of nonpregnant cows was similar $(P=0.19)$ for the 3 treatments $(\mathrm{DO} 60=8.2 \%, \mathrm{DO} 88=11.4 \%$, $\mathrm{PSOv}=11.7 \%)$.

When the hazard of pregnancy was calculated after the end of the VWP for each management strategy, we also noted an effect of treatment $(P=0.01$; Figure 3$)$. In this case, however, cows in the DO60 treatment had greater hazard of pregnancy than cows in PSOv (HR $=1.25,95 \% \mathrm{CI}=1.08-1.45)$ and no differences were observed between the DO60 and DO88 treatments (HR $=1.04,95 \% \mathrm{CI}=0.89-1.20)$. The hazard of pregnancy was also greater for the DO88 than the PSOv treatment $(\mathrm{HR}=1.20,95 \% \mathrm{CI}=1.03-1.40)$. Median and mean days from the end of the VWP to pregnancy were 28 and 63 for DO60, 27 and 62 for DO88, and 46 and 76 for PSOv, respectively. We found no effect of MK30 $(P=0.26)$, and no treatment by parity $(P=0.43)$ or treatment by MK30 interaction $(P=0.27)$ for the hazard of pregnancy after the end of the VWP.

\section{P/AI and Pregnancy Loss After First AI}

Pregnancies per AI $39 \pm 3$ d after first service were similar $(P=0.12)$ when the 3 treatments were compared (Table 1$)$, but were greater $(P<0.01)$ for primiparous $(49.8 \% ; \mathrm{n}=481)$ than multiparous $(35.2 \%$; $\mathrm{n}$ $=747$ ) cows. For the PSOv treatment, $65 \%$ of the cows received $\mathrm{AI}$ at estrus after the second $\mathrm{PGF}_{2 \alpha}$ treatment of Presynch-Ovsynch, whereas the rest of the cows received TAI at $72 \pm 3$ DIM. Average DIM at first service for all cows in PSOv was $61 \mathrm{~d}$ ( $56 \mathrm{~d}$ for cows inseminated at estrus and $72 \mathrm{~d}$ for cows that received TAI). We found a $\sim 7$ percentage point difference in $\mathrm{P} / \mathrm{AI}$ between cows inseminated at estrus $(34.8 \%, \mathrm{n}=270)$ and cows that received TAI $(41.4 \%, \mathrm{n}=145)$ within the PSOv group, but it was not statistically significant $(P=0.19)$. We observed no effect of MK30 $(P=0.65)$ or season $(P=0.79)$, and no treatment by parity $(P=$ $0.70)$, treatment by MK30 $(P=0.58)$, or treatment by season interaction $(P=0.57)$ on $\mathrm{P} / \mathrm{AI}$.

At the time of reconfirmation of pregnancy $95 \pm 3$ $\mathrm{d}$ after $\mathrm{AI}$, we found no effect $(P=0.14$; Table 1$)$ of treatment on $\mathrm{P} / \mathrm{AI}$ but did note an effect of parity $(P$ $<0.01)$, whereby primiparous cows $(46.4 \% ; \mathrm{n}=476)$ had greater $\mathrm{P} / \mathrm{AI}$ than multiparous cows $(31.5 \%$; $\mathrm{n}=$

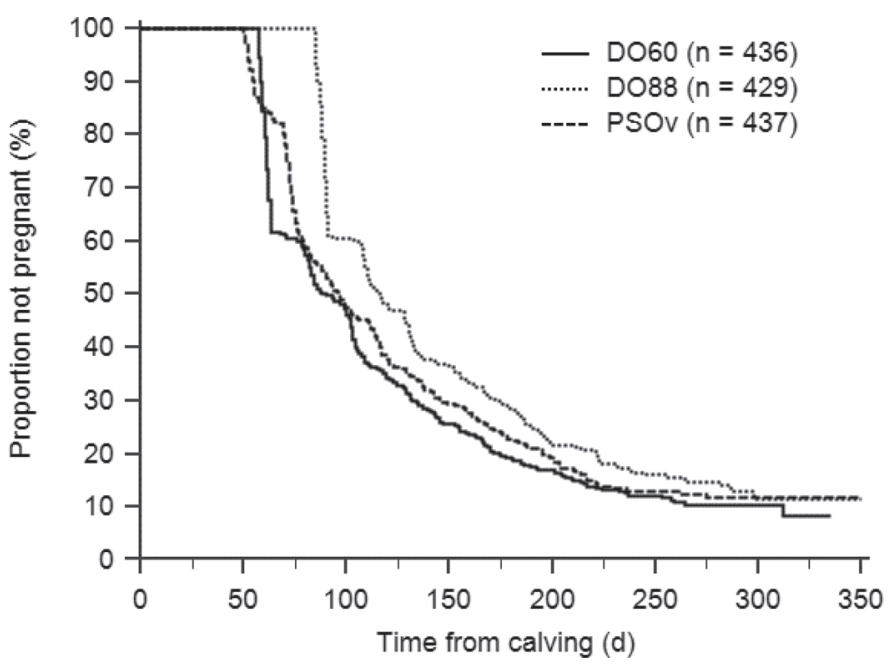

Figure 2. Kaplan-Meier survival curves for time to pregnancy after calving. The hazard of pregnancy was greater $(P<0.01)$ for cows in the DO60 than the DO88 treatment (hazard ratio $=1.53 ; 95 \% \mathrm{CI}=$ 1.32 to 1.78 ) and for cows in the PSOv than the DO88 treatment (hazard ratio $=1.37 ; 95 \% \mathrm{CI}=1.19$ to 1.61 ). No differences were observed between cows in the DO60 and PSOv treatments (hazard ratio $=1.12$; $95 \% \mathrm{CI}=0.96$ to 1.30$)$. DO60 $=$ Double-Ovsynch protocol $(\mathrm{DO})$ at $60 \pm 3$ DIM; DO $88=$ timed AI (TAI) after DO at $88 \pm 3$ DIM; PSOv $=$ combination of insemination after detected estrus and TAI with the Presynch-Ovsynch protocol. 


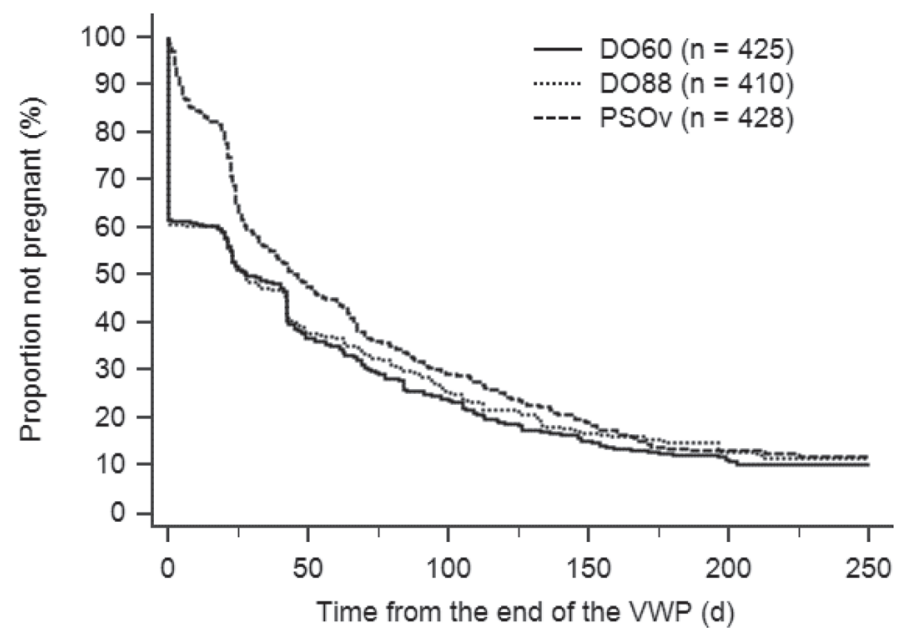

Figure 3. Kaplan-Meier survival curves for days to pregnancy after the end of the voluntary waiting period (VWP; d 0). The hazard of pregnancy was affected by treatment group $(P=0.01)$, whereby cows in the DO60 treatment had greater hazard of pregnancy than cows in the PSOv treatment (hazard ratio $=1.25 ; 95 \% \mathrm{CI}=1.08$ to 1.45 ) and no differences were observed between the DO60 and DO88 treatments (hazard ratio $=1.04 ; 95 \% \mathrm{CI}=0.89$ to 1.20 ). The hazard of pregnancy was also greater for the DO88 than the PSOv treatment (hazard ratio $=1.20 ; 95 \% \mathrm{CI}=1.03$ to 1.40$)$. DO60 = Double-Ovsynch protocol (DO) at $60 \pm 3$ DIM; DO $88=$ timed AI (TAI) after DO at $88 \pm 3$ DIM; PSOv $=$ combination of insemination after detected estrus and TAI with the Presynch-Ovsynch protocol.

737). We observed no effect of MK30 $(P=0.11)$ and season $(P=0.36)$, and there was not a treatment by parity $(P=0.48)$, treatment by MK30 $(P=0.85)$, or treatment by season interaction $(P=0.61)$ for $\mathrm{P} / \mathrm{AI} 95$ $\pm 3 \mathrm{~d}$ after AI.

Pregnancy loss was not affected by treatment $(P=$ $0.76)$ or parity $(P=0.33)$ and we noted no treatment by parity interaction $(P=0.59$; Table 1$)$. In addition, pregnancy loss was not affected by MK30 or season, and there was not a treatment by MK30 or treatment by season interaction $(P>0.10)$.

\section{Reproductive Outcomes for Second and Greater Inseminations}

The proportion of cows inseminated at estrus for second and greater AI was greater $(P<0.01)$ for cows in the PSOv than the DO60 and DO88 treatments (Table 2), and for multiparous $(75.2 \% ; \mathrm{n}=1,301)$ than primiparous $(70.3 \% ; \mathrm{n}=563)$ cows $(P=0.03)$. The interservice interval was similar $(P=0.69$; Table 2$)$ among treatments, and the overall $\mathrm{P} / \mathrm{AI}$ for inseminations at estrus and TAI combined were not affected by treatment $(P=0.16$; Table 2$)$ but were affected by parity $(P<0.01)$, as primiparous cows had greater $\mathrm{P} /$ AI $(38.3 \% ; \mathrm{n}=563)$ than multiparous cows $(28.3 \%$; $\mathrm{n}=1,301)$. Finally, the average total number of AI services up to 350 DIM was similar between treatments $(P=0.87$; Table 2$)$, but it was greater $(P<0.01)$ for multiparous than primiparous cows ( 2.9 vs. 2.3 inseminations, respectively).

\section{Cyclicity Status, Uterine Health, and BCS Before First Service}

Cyclicity status, uterine health, and BCS before first service are presented in Table 3 . The proportion of cyclic cows at baseline tended $(P=0.08)$ to be greater for primiparous $(75.9 \% ; \mathrm{n}=172)$ than multiparous $(68.0 \% ; \mathrm{n}=291)$ cows. In addition, we noted an effect of MK30, whereby the proportion of cows cyclic was greater $(P=0.02)$ for the low $(74.6 \% ; \mathrm{n}=155)$ and medium $(77.2 \% ; \mathrm{n}=154)$ than for the high $(63.7 \% ; \mathrm{n}$ $=154)$ MK30 group. When compared at the beginning of the synchronization protocol for each treatment, we found a greater $(P<0.01)$ proportion of cyclic cows in the DO88 than in for the DO60 and PSOv treatments (Table 3). A tendency $(P=0.07)$ for an effect of parity was also detected [primiparous $=81.7 \%(\mathrm{n}=172)$; multiparous $=74.6 \%(\mathrm{n}=291)] ;$ no effect of MK30 $(P$ $=0.14)$ and no treatment by parity interaction $(P=$

Table 1. Pregnancies per AI (P/AI) and pregnancy loss for lactating dairy cows managed for first service with the Double-Ovsynch or PresynchOvsynch protocol and different duration of the voluntary waiting period

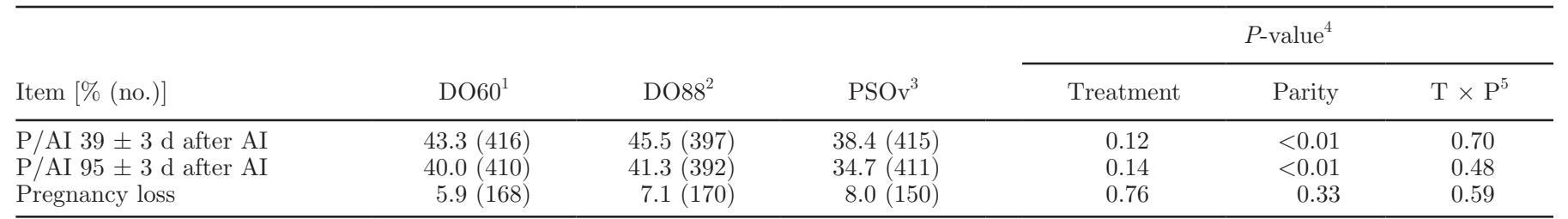

${ }^{1}$ DO60 $=$ first-service timed AI at $60 \pm 3$ DIM after the Double-Ovsynch protocol.

${ }^{2} \mathrm{DO} 88=$ first-service timed AI at $88 \pm 3$ DIM after the Double-Ovsynch protocol.

${ }^{3} \mathrm{PSOv}=$ first service at detected estrus after the second $\mathrm{PGF}_{2 \alpha}$ treatment of Presynch-Ovsynch given at $50 \pm 3 \mathrm{DIM}$ or timed $\mathrm{AI}$ at $72 \pm 3$ DIM after completion of the Presynch-Ovsynch protocol.

${ }^{4}$ Effect of additional explanatory variables are described in the text.

${ }^{5} \mathrm{~T} \times \mathrm{P}=$ treatment by parity interaction. 
Table 2. Effect of first service with the Double-Ovsynch or Presynch-Ovsynch protocol and different duration of the voluntary waiting period on pregnancy per AI after second and greater AI services, interval between AI services, and total number of inseminations up to 350 DIM

\begin{tabular}{|c|c|c|c|c|c|c|}
\hline Item $^{1}$ & $\mathrm{DO}^{2} 0^{2}$ & DO $88^{3}$ & $\mathrm{PSOv}^{4}$ & \multicolumn{3}{|c|}{$P$-value ${ }^{5}$} \\
\hline Interservice interval $(\mathrm{d} \pm \mathrm{SE})$ & $32.7 \pm 0.3$ & $32.4 \pm 0.3$ & $32.8 \pm 0.3$ & 0.69 & 0.01 & 0.79 \\
\hline $\mathrm{P} / \mathrm{AI}[\%$ (no.)] & $35.2(624)$ & $30.2(594)$ & $34.1(646)$ & 0.16 & $<0.01$ & 0.28 \\
\hline Total number of services $( \pm \mathrm{SE})$ & $2.7 \pm 0.1$ & $2.7 \pm 0.1$ & $2.7 \pm 0.1$ & 0.87 & $<0.01$ & 0.83 \\
\hline
\end{tabular}

${ }_{\mathrm{a}, \mathrm{b}}$ Different superscripts within a row indicate significant differences $(P \leq 0.05)$.

${ }^{1} \mathrm{EDAI}=$ cows inseminated at detected estrus; interservice interval = interval (days) between 2 consecutive $\mathrm{AI}$ services; $\mathrm{P} / \mathrm{AI}=$ pregnancies per AI; total number of services $=$ total number of AI services received up to 350 DIM.

${ }^{2}$ DO60 $=$ first-service timed AI at $60 \pm 3$ DIM after the Double-Ovsynch protocol. Second and greater services after detection of estrus or the Ovsynch protocol initiated $32 \pm 3 \mathrm{~d}$ after AI.

${ }^{3}$ DO88 $=$ first-service timed AI at $88 \pm 3$ DIM after the Double-Ovsynch protocol. Second and greater services after detection of estrus or the Ovsynch protocol initiated $32 \pm 3 \mathrm{~d}$ after AI.

${ }^{4} \mathrm{PSOv}=$ first service at detected estrus after the second $\mathrm{PGF}_{2 \alpha}$ treatment of Presynch-Ovsynch given at $50 \pm 3 \mathrm{DIM}$ or timed $\mathrm{AI}$ at $72 \pm 3$ DIM after completion of the Presynch-Ovsynch protocol. Second and greater services after detection of estrus or the Ovsynch protocol initiated $32 \pm 3 \mathrm{~d}$ after AI.

${ }^{5}$ Effect of additional explanatory variables are described in the text.

${ }^{6} \mathrm{~T} \times \mathrm{P}=$ treatment by parity interaction.

0.97) was observed at this time point. At -5 or -10 $\mathrm{d}$ before the end of the VWP, the proportion of cyclic cows was greater for the DO60 and DO88 than the PSOv treatment, but no effect of parity $(P=0.34)$ or
MK30 $(P=0.21)$ was observed and no treatment by parity interaction $(P=0.57)$.

We observed no effect of treatment, parity, or MK30, and no treatment by parity interaction for the propor-

Table 3. Cyclicity status, uterine health, and BCS for lactating dairy cows that received first-service AI after the Double-Ovsynch or PresynchOvsynch protocol and different duration of the voluntary waiting period

\begin{tabular}{|c|c|c|c|c|c|c|}
\hline \multirow[b]{2}{*}{ Item } & \multicolumn{3}{|c|}{ Treatment } & \multicolumn{3}{|c|}{$P$-value } \\
\hline & $\mathrm{DO}^{1} 0^{1}$ & $\mathrm{DO} 88^{2}$ & $\mathrm{PSOv}^{3}$ & Treatment & Parity & $\mathrm{T} \times \mathrm{P}^{4}$ \\
\hline Baseline & $70.9(165)$ & $71.8(142)$ & $73.7(156)$ & 0.88 & 0.08 & 0.95 \\
\hline Beginning of $\mathrm{SP}^{6}$ & $70.9^{\mathrm{a}}(165)$ & $87.5^{\mathrm{b}}(142)$ & $73.6^{\mathrm{a}}(156)$ & $<0.01$ & 0.07 & 0.97 \\
\hline-5 or $-10 \mathrm{~d}$ of VWP end & $95.2^{\mathrm{a}}(164)$ & $95.0^{\mathrm{a}}(142)$ & $83.1^{\mathrm{b}}(155)$ & $<0.01$ & 0.34 & 0.57 \\
\hline \multicolumn{7}{|l|}{$\mathrm{PVD}^{8}[\%$ (no.)] } \\
\hline-5 or $-10 \mathrm{~d}$ of VWP end & $22.6(53)$ & $14.0(50)$ & $12.4(81)$ & 0.26 & 0.23 & 0.47 \\
\hline \multicolumn{7}{|l|}{$\mathrm{PMN}^{9}(\% \pm \mathrm{SE})$} \\
\hline Baseline & $13.0 \pm 2.9$ & $15.9 \pm 3.0$ & $13.0 \pm 2.2$ & 0.56 & 0.74 & 0.62 \\
\hline Beginning of SP & $13.0 \pm 2.9$ & $8.2 \pm 2.5$ & $13.0 \pm 2.2$ & 0.31 & 0.76 & 0.42 \\
\hline-5 or $-10 \mathrm{~d}$ of VWP end 7 & $8.8 \pm 2.3^{\mathrm{a}}$ & $3.5 \pm 1.7^{\mathrm{b}}$ & $9.2 \pm 1.8^{\mathrm{a}}$ & 0.03 & 0.38 & 0.25 \\
\hline \multicolumn{7}{|l|}{ BCS $\geq 2.75[\%$ (nо.) $]$} \\
\hline Baseline & $88.5(165)$ & $88.7(142)$ & $87.2(156)$ & 0.87 & $<0.01$ & 0.79 \\
\hline
\end{tabular}

${ }_{\mathrm{a}, \mathrm{b}}$ Different superscripts within a row indicate significant differences $(P \leq 0.05)$.

${ }^{1}$ DO60 $=$ first-service timed AI at $60 \pm 3$ DIM after the Double-Ovsynch protocol.

${ }^{2}$ DO 88 = first-service timed AI at $88 \pm 3$ DIM after the Double-Ovsynch protocol.

${ }^{3} \mathrm{PSOv}=$ first service at detected estrus after the second $\mathrm{PGF}_{2 \alpha}$ treatment of Presynch-Ovsynch given at $50 \pm 3 \mathrm{DIM}$ or timed $\mathrm{AI}$ at $72 \pm 3$ DIM after completion of the Presynch-Ovsynch protocol.

${ }^{4} \mathrm{~T} \times \mathrm{P}=$ treatment by parity interaction.

${ }^{5}$ Cyclic $=$ cows with progesterone concentration $>1 \mathrm{ng} / \mathrm{mL}$.

${ }^{6}$ Beginning of $\mathrm{SP}=$ samples collected at the beginning of the synchronization protocol.

${ }^{7}-10 \mathrm{~d}$ of voluntary waiting period (VWP) end $=50 \pm 3$ DIM for DO60 and $78 \pm 3$ DIM for DO88; $-5 \mathrm{~d}$ of VWP end $=45 \pm 3$ DIM for PSOv.

${ }^{8} \mathrm{PVD}=$ cows with purulent vaginal discharge (Metricheck score $\geq 2$; Simcro, Hamilton, New Zealand).

${ }^{9} \mathrm{PMN}=$ percentage polymorphonuclear cells in uterine cytology sample. 
tion of cows with PVD at any of the time points evaluated $(P>0.10$; Table 3$)$. The PMN percentage observed in uterine cytology samples was similar between treatments at the beginning of the synchronization protocol for each treatment $(P=0.31)$, but it was less $(P=0.03)$ at -5 to $-10 \mathrm{~d}$ before the end of the VWP end for the DO88 than the DO60 and PSOv treatments (Table 3). No effect of parity and MK30 was detected, and we found no treatment by parity interaction at any of the time points analyzed $(P>0.10)$.

At baseline, the proportion of cows with $\mathrm{BCS} \geq 2.75$ was greater $(P<0.01)$ for primiparous $(95.4 \%$; $\mathrm{n}=$ $172)$ than multiparous $(72.9 \% ; \mathrm{n}=291)$ cows. At the beginning of the synchronization protocol, we noted an effect of treatment $(P=0.02)$ and parity $(P<0.01)$, whereby the proportion of cows with $\mathrm{BCS} \geq 2.75$ was greater for cows in the DO88 than in the DO60 and PSOv treatments (Table 3$)$. A greater $(P<0.01)$ proportion of primiparous $(96.4 \% ; \mathrm{n}=172)$ than multiparous $(78.7 \% ; \mathrm{n}=291)$ cows had $\mathrm{BCS} \geq 2.75$. At -5 or $-10 \mathrm{~d}$ before the end of the VWP, the proportion of cows with $\mathrm{BCS} \geq 2.75$ was greater $(P=0.03)$ for the DO88 than the PSOv treatment, whereas the DO60 treatment was similar to the other 2 treatments. We also observed an effect of parity $(P<0.01)$ and MK30 $(P=0.01)$ on the proportion of cows with BCS $\geq 2.75$. A greater proportion of primiparous $(96.6 \% ; \mathrm{n}=/ 169)$ than multiparous cows $(79.5 \% ; \mathrm{n}=290)$, and a greater proportion of cows with low $(95.4 \% ; \mathrm{n}=236)$ than medium $(89.3 \% ; \mathrm{n}=233)$ and high $(87.0 \% ; \mathrm{n}=201)$ milk production had $\mathrm{BCS} \geq 2.75$.

\section{Herd Exit Pattern}

The effect of treatment on time to herd exit during the experiment was analyzed separately for each parity group because of the well-known differences in herd exit dynamics between primiparous and multiparous cows. In this experiment, the hazard of culling was, as expected, greater $(P<0.01)$ for multiparous than primiparous cows ( $\mathrm{HR}=2.41,95 \% \mathrm{CI}=1.89-3.08)$. For primiparous cows, the hazard of culling was similar $(P=0.22)$ between treatments (DO60 vs. DO88: HR $=$ $1.12,95 \% \mathrm{CI}=0.64-1.96$; DO60 vs. PSOv: $\mathrm{HR}=0.72$, $95 \% \mathrm{CI}=0.43-1.20 ; \mathrm{DO} 88$ vs. $\mathrm{PSOv}: \mathrm{HR}=0.64,95 \%$ $\mathrm{CI}=0.38-1.09$; Figure $4 \mathrm{~A})$. Mean days from calving to herd exit were 318 for DO60, 328 for DO88, and 323 for PSOv. For multiparous cows, we noted an effect of treatment $(P=0.02)$, whereby cows in DO88 and $\mathrm{PSOv}$ treatments had greater hazard of culling than cows in the DO60 treatment (DO88 vs. DO60: HR $=1.49,95 \% \mathrm{CI}=1.11-2.00 ;$ PSOv vs. $\mathrm{DO} 60: \mathrm{HR}=$ $1.39,95 \% \mathrm{CI}=1.03-1.85$; Figure 4B). No difference was observed between the DO88 and PSOv treatments
$(\mathrm{HR}=1.07,95 \% \mathrm{CI}=0.82-1.41)$. Mean days from calving to exit from the herd were 299 for DO60, 294 for DO88, and 290 for PSOv. In both parity groups, milk production affected $(P<0.01)$ the hazard of culling because cows in the low-MK30 group had greater hazard of culling than cows in the medium $(\mathrm{HR}=2.08$, $95 \% \mathrm{CI}=1.62-2.67)$ and high $(\mathrm{HR}=2.17,95 \% \mathrm{CI}=$ 1.67-2.78) groups (Figure 4C). Mean days from calving to herd exit were 285 for low MK30, 323 for medium MK30, and 320 for high MK30.

As expected, the proportion of cows sold was greater $(P<0.01)$ for multiparous $(31.9 \% ; \mathrm{n}=801)$ than primiparous $(13.9 \%$; $\mathrm{n}=502)$ cows. For the primiparous group, the proportion of cows sold was similar between treatments $(P=0.65)$, but for the multiparous group it was greater $(P=0.04)$ for DO88 than DO60 (Table 4). No differences were observed for PSOv (31.6\%) and the other 2 treatments. The proportion of cows that died did not differ within the primiparous $(P=$ $0.31)$ and multiparous cow group $(P=0.20$; Table 4$)$. Consequently, the total proportion of cows that left the herd during the experiment (sold plus died) was similar among treatment groups within primiparous $(P=$ $0.36)$, but it was greater for the DO88 than the DO60 treatment within the multiparous cow group (Table 4).

\section{DISCUSSION}

We investigated the effect of different management strategies for first service and VWP duration on time to pregnancy during lactation in dairy cows. The strategies compared, which represented typical programs for first service in commercial dairy farms (Caraviello et al., 2006; Ferguson and Skidmore, 2013; Scott, 2016), varied in method of submission to insemination, synchronization protocol, and VWP duration. Our data supported the hypothesis that submission of cows to the first service after a shorter VWP, either after all TAI (DO60) or a combination of insemination at estrus and TAI (PSOv), reduced time to pregnancy during lactation. Our results for time to pregnancy are in agreement with previous studies, which reported reduced time to pregnancy after calving in spite of lower $\mathrm{P} /$ AI to the first service in cows with shorter rather than extended VWP (Tenhagen et al., 2003; Gobikrushanth et al., 2014).

Results for time to pregnancy were consistent across parity groups regardless of differences in $\mathrm{P} / \mathrm{AI}$ and hazard of pregnancy between parities. These data suggest that extending the VWP without a substantial gain in $\mathrm{P} / \mathrm{AI}$ to compensate for pregnancies generated earlier in lactation when a shorter VWP program is used, would likely delay overall time to pregnancy. The effect of shorter VWP was also evident for cows in the PSOv 

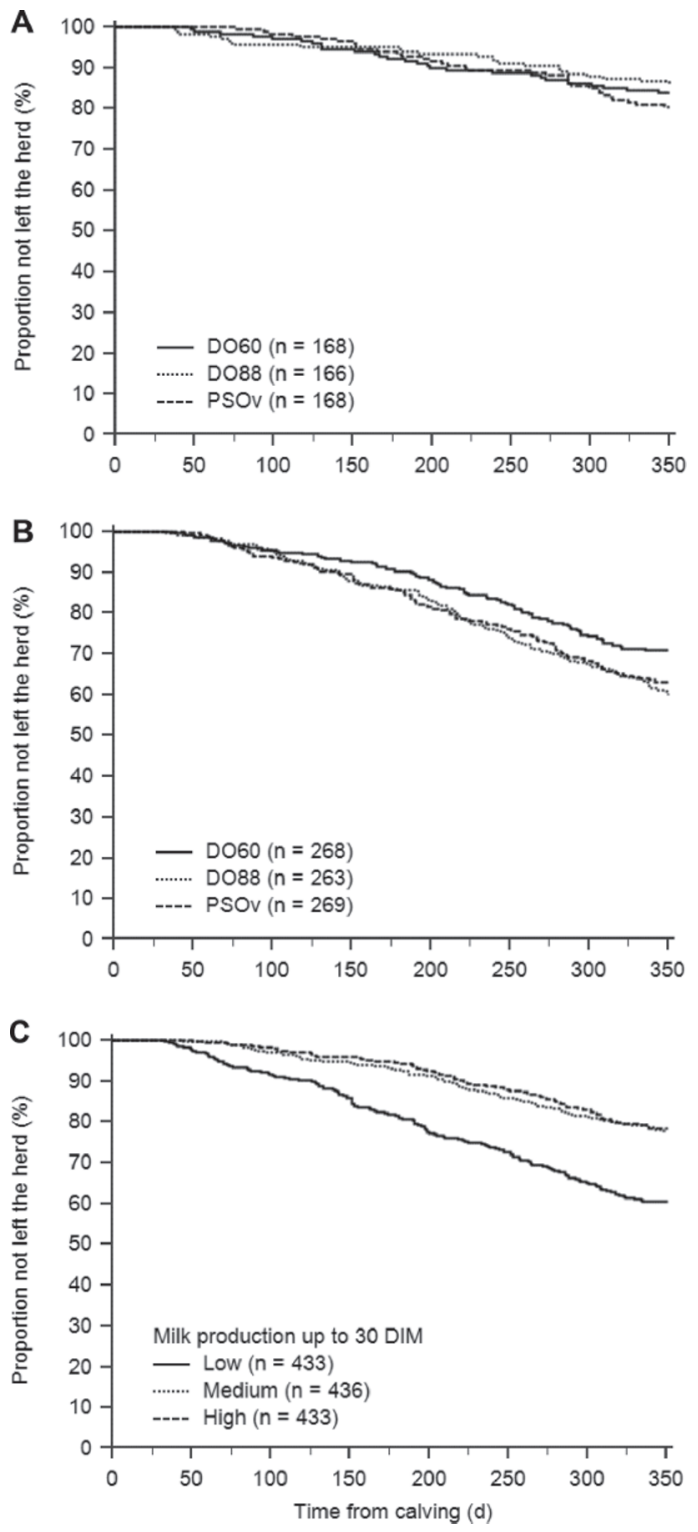

Figure 4. (A) Kaplan-Meier survival curves for time to herd exit after calving for primiparous cows. The hazard of culling was similar $(P=0.22)$ between treatments (DO60 vs. DO88: hazard ratio $=1.12$, $95 \% \mathrm{CI}=0.64$ to $1.96 ;$ DO60 vs. PSOv: hazard ratio $=0.72,95 \% \mathrm{CI}$ $=0.43$ to $1.20 ;$ DO88 vs. PSOv: hazard ratio $=0.64,95 \% \mathrm{CI}=0.38$ to 1.09). (B) Kaplan-Meier survival curves for time to herd exit after calving for multiparous cows. The hazard of culling was affected by treatment $(P=0.02)$, whereby cows in the DO88 and PSOv treatments had greater hazard of culling than cows in the DO60 treatments (DO88 vs. DO60: hazard ratio $=1.49,95 \% \mathrm{CI}=1.11$ to 2.00 ; $\mathrm{PSOv}$ vs. DO60: hazard ratio $=1.39,95 \% \mathrm{CI}=1.03$ to 1.85 ). No difference was observed between the DO88 and the PSOv treatments (hazard ratio $=1.07,95 \% \mathrm{CI}=0.82$ to 1.41 ). (C) Kaplan-Meier survival curves for time to herd exit after calving according to milk production accumulated up to 30 DIM (MK30). The hazard of culling was affected by MK30, whereby cows in the low milk production group had greater hazard of culling than cows in the medium (hazard ratio $=2.08,95 \%$ $\mathrm{CI}=1.62$ to 2.67 ) and high (hazard ratio $=2.17,95 \% \mathrm{CI}=1.67$ to 2.78) MK30 group. DO60 = Double-Ovsynch protocol (DO) at $60 \pm$ 3 DIM; DO88 = timed AI (TAI) after DO at $88 \pm 3$ DIM; PSOv $=$ combination of insemination after detected estrus and TAI with the Presynch-Ovsynch protocol. treatment, which, in spite of a 7-percentage point numerically lower P/AI to the first service than cows in the DO88 treatment, had reduced time to pregnancy. Collectively, data from the current experiment suggest that earlier opportunities for reinsemination when cows are managed with a shorter VWP (i.e., $28 \mathrm{~d}$ for all TAI and $38 \mathrm{~d}$ for combined approach) compensate for an overall reduction in $\mathrm{P} / \mathrm{AI}$ to the first service of up to 7 percentage points.

A 10-d shorter VWP for the combined strategy with PSOv resulted in similar time to pregnancy after calving to the DO60 treatment, which entailed use of $100 \%$ TAI. This could be explained by the combined effect of (1) reasonable $\mathrm{P} / \mathrm{AI}$ (i.e., $34.8 \%$ ) for the $65 \%$ of cows inseminated at estrus after Presynch and (2) similar $\mathrm{P} / \mathrm{AI}$ for TAI services after completion of PresynchOvsynch (i.e., 41.4\%) and Double-Ovsynch at 60 DIM (i.e., $41.8 \%$ ). These data suggest that submitting cows for insemination at estrus and TAI with the PresynchOvsynch protocol may result in similar reproductive performance to using all TAI with a program such as Double-Ovsynch when average DIM at first service are the same (e.g., $60 \mathrm{~d}$ in our experiment). Certainly, the success of combined programs may be more dependent upon the ability of farm personnel to accurately detect and inseminate cows in estrus and the success of cows that receive TAI. Poor detection of estrus results in greater average DIM to the first service because most cows receive TAI at later DIM, whereas low $\mathrm{P} /$ $\mathrm{AI}$ increases the proportion of cows that need multiple inseminations at later DIM to conceive.

Unlike the results observed using calving as reference point, when time to pregnancy was evaluated after the end of the VWP, the hazard of pregnancy and survival curves reflected the benefit of all TAI. This finding was likely related to differences in the pattern of submission to the first service and resulting $\mathrm{P} / \mathrm{AI}$ because, unlike all TAI programs, combining insemination of cows at estrus and TAI with Presynch-Ovsynch results in a wider range of days to the first service. Although up to $50 \%$ or more of the cows may be inseminated at estrus within a week of the VWP end, the rest of the cows receive TAI 20 to $24 \mathrm{~d}$ after the end of the VWP depending on the interval (i.e., 10-14 d) from Presynch to Ovsynch (Chebel et al., 2006; Stevenson et al., 2012; Giordano et al., 2016). Poor P/AI for inseminations at estrus are also problematic because cows not pregnant after first service at estrus have an additional delay to conception. Collectively, our results suggest that both shorter VWP and the greatest possible $\mathrm{P} / \mathrm{AI}$ for inseminations at estrus are critical to achieve the same or better reproductive performance with programs that combine AI at estrus and TAI than all TAI programs. This is because the bimodal distribution of AI services 
Table 4. Proportion of cows sold, dead, and total proportion that left the herd (sold and dead) for lactating dairy cows that received first-service AI after the Double-Ovsynch or Presynch-Ovsynch protocol and different duration of the voluntary waiting period

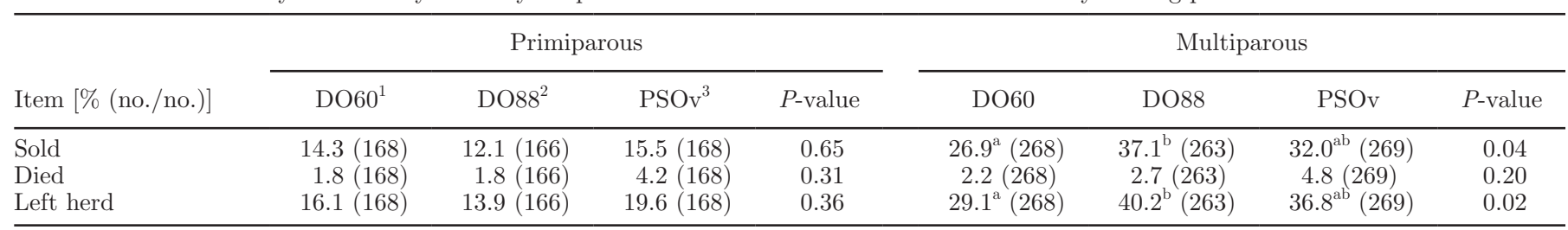

${ }^{\mathrm{a}, \mathrm{b}}$ Different superscripts within a row indicate significant differences $(P \leq 0.05)$ within the same parity.

${ }^{1}$ DO60 $=$ first-service timed AI at $60 \pm 3$ DIM after the Double-Ovsynch protocol. Second and greater services after detection of estrus or the Ovsynch protocol initiated $32 \pm 3 \mathrm{~d}$ after AI.

${ }^{2}$ DO88 $=$ first-service timed AI at $88 \pm 3$ DIM after the Double-Ovsynch protocol. Second and greater services after detection of estrus or the Ovsynch protocol initiated $32 \pm 3 \mathrm{~d}$ after AI.

${ }^{3} \mathrm{PSOv}=$ first service at detected estrus after the second $\mathrm{PGF}_{2 \alpha}$ treatment of Presynch-Ovsynch given at $50 \pm 3$ DIM or timed AI at $72 \pm 3$ DIM after completion of the Presynch-Ovsynch protocol. Second and greater services after detection of estrus or the Ovsynch protocol initiated $32 \pm 3 \mathrm{~d}$ after $\mathrm{AI}$

generated with combined programs leads to a wider range of DIM at first service and the additional delay to achieve pregnancy caused by failure to conceive after first service at detected estrus.

As expected, a longer VWP allowed a greater proportion of cows in the DO88 treatment to resolve anovulation and have better body condition at the beginning of the synchronization protocol. Conversely, differences in cyclicity status and BCS at -5 or $-10 \mathrm{~d}$ before the end of the VWP were only observed between the DO88 and the PSOv treatments. These differences, or lack thereof, were likely because of the well-known effect of GnRH-based protocols on reducing anovulation (Souza et al., 2008; Herlihy et al., 2012; Ayres et al., 2013) and because of the greater DIM difference at this time point between the DO88 and PSOv treatments, which allowed cows in the DO88 treatment to recover more body condition than cows in PSOv. Cows in the DO88 treatment also had better uterine health (PMN percent only) immediately before the end of the VWP, supporting the notion that uterine inflammation after calving is reduced over time (Gautam et al., 2009; Sheldon et al., 2009; LeBlanc, 2014; Vieira-Neto et al., 2014).

The detrimental effects of anovulation (Santos et al., 2004; Ribeiro et al., 2016; Bruinjé et al., 2017), poor uterine health (Gilbert et al., 2005; Barlund et al., 2008; Dubuc et al., 2010), and suboptimal BCS (Souza et al., 2007; Souza et al., 2008; Carvalho et al., 2014a) on first-service $\mathrm{P} / \mathrm{AI}$ have been extensively documented and were the basis for our expectation of greater $\mathrm{P} /$ AI in cows with an 88-d VWP. Nevertheless, the gain in $\mathrm{P} / \mathrm{AI}$ due to the extended VWP was insufficient to compensate for the greater number of pregnancies created up to 91 DIM (i.e., end DIM range to the first service in the DO88 treatment) by the programs with shorter VWP. Under the conditions of our current experiment, the overall proportion of pregnant cows after first service (accounting for cows that left the herd before first service and pregnancy losses) in the DO88 treatment should have been at least 9 to 11 percentage points greater to compensate for the longer VWP compared with the PSOv and DO60 groups, respectively. Achieving the P/AI needed to compensate for a $28-\mathrm{d}$ extension of the VWP, as in our experiment, may be possible as fertility programs such as Double-Ovsynch continue evolving to further increase P/AI (Giordano et al., 2013; Carvalho et al., 2015; Wiltbank et al., 2015). In addition, other improvements in dairy herd management that may contribute to improved uterine health, earlier resumption of cyclicity, and recovery of body reserves may be used in combination with extended VWP and fertility programs to maximize P/AI to first service.

Our experiment was not designed to and was underpowered to detect statistically significant differences in $\mathrm{P} / \mathrm{AI}$ to the first service as observed between the 3 treatments. Interestingly, $\mathrm{P} / \mathrm{AI}$ was similar for the DO60 and DO88 treatments, suggesting that the cyclicity status, uterine health (PMN percent only), and BCS differences observed after extending the VWP from 60 to 88 DIM were insufficient to substantially increase $\mathrm{P} / \mathrm{AI}$. We speculated that the lack of difference was, at least in part, due to the high proportion of cows properly synchronized with Double-Ovsynch regardless of DIM at the beginning of the protocol and the resolution of anovulation in most cows treated with the Double-Ovsynch protocol (Souza et al., 2008; Herlihy et al., 2012; Ayres et al., 2013). Further, the differences in proportion of cows with poor uterine health (PMN percent only) between the DO60 and DO88 treatments and the effect of improved uterine health on $\mathrm{P} / \mathrm{AI}$ were also insufficient to generate overall differences in $\mathrm{P} / \mathrm{AI}$. Interestingly, we observed a numerical difference of $\sim 6$ percentage points $(P=0.38)$ for $\mathrm{P} / \mathrm{AI}$ in favor of the 
DO88 treatment for primiparous cows but similar P/ AI for multiparous cows (data not shown), suggesting that only primiparous cows may benefit from the VWP extension. Although data for primiparous cows in our experiment were underpowered to detect a statistical difference in spite of a 6-percentage point difference in $\mathrm{P} / \mathrm{AI}$, they are an agreement with a larger data set for an experiment conducted in 3 commercial farms in which we observed a statistically significant increase in $\mathrm{P} / \mathrm{AI}$ for primiparous $(\mathrm{DO} 60=46.2 \%$ and $\mathrm{DO} 88$ $=55.0 \%$ ) but not multiparous cows with the extended VWP $($ DO60 $=36.2 \%$ and DO88 $=40.1 \%$; Stangaferro et al., 2018). Further investigation is necessary to elucidate the effect of parity on $\mathrm{P} / \mathrm{AI}$ after extending the VWP in lactating dairy cows.

Differences in rate of pregnancy establishment during lactation not only affect the hazard of pregnancy, but also the herd exit dynamics, because pregnancy status along with milk production level and number of lactations (data from this experiment) are major drivers of culling in dairy herds (Rajala-Schultz and Gröhn, 1999; De Vries et al., 2010; Pinedo et al., 2010). Cows with fewer lactations, pregnant cows, and cows with higher milk production level are less likely to be removed from a herd. In our experiment, this was evident, as we observed differences in the herd exit dynamics among treatments for multiparous cows only. Cows in the DO88 and PSOv treatments had a greater hazard of herd exit than cows in the DO60 treatment, and the proportion of cows sold was greater for multiparous cows in the DO88 than the DO60 treatment. At least in part, these differences were explained by the effect of extended VWP on pregnancy establishment and herd exit dynamics, as extending the VWP resulted in delayed pregnancy. Nevertheless, the effect of treatments on timing of pregnancy cannot fully explain our observations for multiparous cows in the $\mathrm{PSOv}$ treatment because the hazard of pregnancy after calving in these cows was similar to cows in the DO60 treatment.

The effect of time to pregnancy during lactation on individual cow and dairy herd profitability is affected by a complex interplay of several factors, including but not limited to income over feed cost, reproductive management costs, fixed operating costs, and replacement costs (De Vries, 2006; Inchaisri et al., 2011; Giordano et al., 2012). Moreover, these parameters are affected by multiple others factors that should be accounted for when considering the effects of first-service management strategies on profitability. Therefore, the observed differences in reproductive performance and herd exit dynamics reported in our experiment likely had a complex effect on profitability that was not evaluated in sufficient detail to make inferences about economic differences among the strategies compared. A detailed evaluation of the effects on profitability of the management strategies compared will be presented in a separate manuscript.

\section{CONCLUSIONS}

Data from the present experiment demonstrated that reproductive management strategies that resulted in average DIM to the first service of $\sim 60 \mathrm{~d}$ through a combination of AI at estrus with TAI (PSOv) or all TAI (DO60) resulted in same hazard of pregnancy and overall time to pregnancy after calving. These 2 strategies, however, reduced time to pregnancy during lactation when compared with an all-TAI program (DO88) with a VWP of $88 \mathrm{~d}$. Most of the reduction in time to pregnancy for the groups with shorter VWP was explained by earlier opportunities for reinsemination. The observed improvement in cyclicity status, uterine health (PMN percent only), and BCS for cows with an 88-d VWP was insufficient to generate the number of pregnancies at first service needed to compensate for delayed first insemination. Beyond time to pregnancy, the first-service management strategies tested in this experiment led to differences in the hazard of herd exit, which were also affected by parity and milk production level. Cows with low milk production level regardless of treatment were more likely to leave the herd, and, within the multiparous cow group, cows that received all TAI with a VWP duration of $60 \mathrm{~d}$ were less likely to leave the herd than cows in the other treatments. Therefore, data from this experiment suggest that the effect of first-service management strategies on dairy herd performance depends upon complex interactions between the pattern of insemination, pregnancy per AI, and herd exit dynamics, all of which may vary for primiparous and multiparous cows.

\section{ACKNOWLEDGMENTS}

This research was financially supported through a grant (AOR 13-006) from the New York Farm Viability Institute (Syracuse, NY) to J. O. Giordano. We thank the commercial dairy farm that participated of this research for their support and the use of their cows and facilities. We also extend our gratitude to Merck Animal Health (Madison, NJ) for providing the hormonal products used to synchronize ovulation, and to Accelerated Genetics (Baraboo, WI) for providing part of the semen used in this experiment. Finally, we thank Jim Ehrlich from DairySights LLC (Argyle, NY) for his calculations of daily milk production using the MilkBot model. 


\section{REFERENCES}

Abramson, J. H. 2011. WINPEPI updated: Computer programs for epidemiologists, and their teaching potential. Epidemiol. Perspect. Innov. 8:1.

Ayres, H., R. Ferreira, A. Cunha, R. Araújo, and M. Wiltbank. 2013. Double-Ovsynch in high-producing dairy cows: Effects on progesterone concentrations and ovulation to $\mathrm{GnRH}$ treatments. Theriogenology 79:159-164.

Barlund, C. S., T. Carruthers, C. Waldner, and C. Palmer. 2008. A comparison of diagnostic techniques for postpartum endometritis in dairy cattle. Theriogenology 69:714-723.

Bello, N. M., J. P. Steibel, and J. R. Pursley. 2006. Optimizing ovulation to first GnRH improved outcomes to each hormonal injection of Ovsynch in lactating dairy cows. J. Dairy Sci. 89:3413-3424.

Borchardt, S., P. Haimerl, and W. Heuwieser. 2016. Effect of insemination after estrous detection on pregnancy per artificial insemination and pregnancy loss in a Presynch-Ovsynch protocol: A metaanalysis. J. Dairy Sci. 99:2248-2256.

Borchardt, S., P. Haimerl, A. Pohl, and W. Heuwieser. 2017. Evaluation of prostaglandin $\mathrm{F} 2 \alpha$ versus prostaglandin $\mathrm{F} 2 \alpha$ plus gonadotropin-releasing hormone as Presynch methods preceding an Ovsynch in lactating dairy cows: A meta-analysis. J. Dairy Sci. 100:4065-4077.

Bruinjé, T. C., M. G. Colazo, M. Gobikrushanth, and D. J. Ambrose. 2017. Relationship between commencement and frequency of early postpartum luteal activity, parity and insemination outcomes based on in-line milk progesterone profiles in Canadian Holstein cows. Theriogenology 100:32-41.

Butler, W. R. 2003. Energy balance relationships with follicular development, ovulation and fertility in postpartum dairy cows. Livest. Prod. Sci. 83:211-218.

Caraviello, D. Z., K. A. Weigel, P. M. Fricke, M. C. Wiltbank, M. J. Florent, N. B. Cook, K. V. Nordlund, N. R. Zwald, and C. L. Rawson. 2006. Survey of management practices on reproductive performance of dairy cattle on large US commercial farms. J. Dairy Sci. 89:4723-4735.

Carvalho, P. D., A. Souza, M. Amundson, K. Hackbart, M. Fuenzalida, M. Herlihy, H. Ayres, A. Dresch, L. Vieira, and J. Guenther. 2014a. Relationships between fertility and postpartum changes in body condition and body weight in lactating dairy cows. J. Dairy Sci. 97:3666-3683.

Carvalho, P. D., J. N. Guenther, M. J. Fuenzalida, M. C. Amundson, M. C. Wiltbank, and P. M. Fricke. 2014b. Presynchronization using a modified Ovsynch protocol or a single gonadotropin-releasing hormone injection $7 \mathrm{~d}$ before an Ovsynch-56 protocol for submission of lactating dairy cows to first timed artificial insemination. J. Dairy Sci. 97:6305-6315.

Carvalho, P. D., M. C. Wiltbank, and P. M. Fricke. 2015. Manipulation of progesterone to increase ovulatory response to the first $\mathrm{GnRH}$ treatment of an Ovsynch protocol in lactating dairy cows receiving first timed artificial insemination. J. Dairy Sci. 98:8800-8813.

Chebel, R. C., and J. Santos. 2010. Effect of inseminating cows in estrus following a presynchronization protocol on reproductive and lactation performances. J. Dairy Sci. 93:4632-4643.

Chebel, R. C., J. E. Santos, R. L. Cerri, H. M. Rutigliano, and R. Bruno. 2006. Reproduction in dairy cows following progesterone insert presynchronization and resynchronization protocols. J. Dairy Sci. 89:4205-4219.

Cheong, S. H., O. G. S. Filho, V. A. Absalón-Medina, S. H. Pelton, W. R. Butler, and R. O. Gilbert. 2016. Metabolic and Endocrine Differences Between Dairy Cows That Do or Do Not Ovulate First Postpartum Dominant Follicles. Biol. Reprod. 94:18.

De Vries, A. 2006. Economic value of pregnancy in dairy cattle. J. Dairy Sci. 89:3876-3885.

De Vries, A., J. Olson, and P. Pinedo. 2010. Reproductive risk factors for culling and productive life in large dairy herds in the eastern United States between 2001 and 2006. J. Dairy Sci. 93:613-623.

Dubuc, J., T. Duffield, K. Leslie, J. Walton, and S. LeBlanc. 2010. Definitions and diagnosis of postpartum endometritis in dairy cows. J. Dairy Sci. 93:5225-5233.
Edmonson, A., I. Lean, L. Weaver, T. Farver, and G. Webster. 1989. A body condition scoring chart for Holstein dairy cows. J. Dairy Sci. $72: 68-78$.

Ehrlich, J. 2011. Quantifying shape of lactation curves, and benchmark curves for common dairy breeds and parities. Bov. Pract. 45:88.

Ferguson, J. D., and A. Skidmore. 2013. Reproductive performance in a select sample of dairy herds. J. Dairy Sci. 96:1269-1289.

Fricke, P. M., J. O. Giordano, A. Valenza, G. Lopes Jr., M. C. Amundson, and P. D. Carvalho. 2014. Reproductive performance of lactating dairy cows managed for first service using timed artificial insemination with or without detection of estrus using an activitymonitoring system. J. Dairy Sci. 97:2771-2781.

Gautam, G., T. Nakao, M. Yusuf, and K. Koike. 2009. Prevalence of endometritis during the postpartum period and its impact on subsequent reproductive performance in two Japanese dairy herds. Anim. Reprod. Sci. 116:175-187.

Gilbert, R. O., S. T. Shin, C. L. Guard, H. N. Erb, and M. Frajblat. 2005. Prevalence of endometritis and its effects on reproductive performance of dairy cows. Theriogenology 64:1879-1888.

Giordano, J. O., A. Kalantari, P. Fricke, M. Wiltbank, and V. Cabrera. 2012. A daily herd Markov-chain model to study the reproductive and economic impact of reproductive programs combining timed artificial insemination and estrus detection. J. Dairy Sci. 95:5442-5460.

Giordano, J. O., M. J. Thomas, G. Catucuamba, M. D. Curler, R. Wijma, M. L. Stangaferro, and M. Masello. 2016. Effect of extending the interval from Presynch to initiation of Ovsynch in a PresynchOvsynch protocol on fertility of timed artificial insemination services in lactating dairy cows. J. Dairy Sci. 99:746-757.

Giordano, J. O., M. C. Wiltbank, P. M. Fricke, S. Bas, R. Pawlisch, J. N. Guenther, and A. B. Nascimento. 2013. Effect of increasing GnRH and PGF $2 \alpha$ dose during Double-Ovsynch on ovulatory response, luteal regression, and fertility of lactating dairy cows. Theriogenology 80:773-783.

Gobikrushanth, M., A. De Vries, J. Santos, C. Risco, and K. Galvão. 2014. Effect of delayed breeding during the summer on profitability of dairy cows. J. Dairy Sci. 97:4236-4246.

Gumen, A., A. Keskin, G. Yilmazbas-Mecitoglu, E. Karakaya, A. Alkan, H. Okut, and M. C. Wiltbank. 2012. Effect of presynchronization strategy before Ovsynch on fertility at first service in lactating dairy cows. Theriogenology 78:1830-1838.

Herlihy, M. M., J. Giordano, A. Souza, H. Ayres, R. Ferreira, A. Keskin, A. Nascimento, J. Guenther, J. Gaska, and S. Kacuba. 2012. Presynchronization with Double-Ovsynch improves fertility at first postpartum artificial insemination in lactating dairy cows. J. Dairy Sci. 95:7003-7014.

Inchaisri, C., R. Jorritsma, P. Vos, G. Van der Weijden, and H. Hogeveen. 2011. Analysis of the economically optimal voluntary waiting period for first insemination. J. Dairy Sci. 94:3811-3823.

Kawashima, C., M. Matsui, T. Shimizu, and A. Miyamoto. 2012. Nutritional factors that regulate ovulation of the dominant follicle during the first follicular wave postpartum in high-producing dairy cows. J. Reprod. Dev. 58:10-16.

LeBlanc, S. J. 2014. Reproductive tract inflammatory disease in postpartum dairy cows. Animal 8:54-63.

LeBlanc, S. J., T. F. Duffield, K. E. Leslie, K. G. Bateman, G. P. Keefe, J. S. Walton, and W. H. Johnson. 2002. Defining and diagnosing postpartum clinical endometritis and its impact on reproductive performance in dairy cows. J. Dairy Sci. 85:2223-2236.

Machado, V. S., R. Neves, F. Lima, and R. Bicalho. 2017. The effect of Presynch-Ovsynch protocol with or without estrus detection on reproductive performance by parity, and the long-term effect of these different management strategies on milk production, reproduction, health and survivability of dairy cows. Theriogenology 93:84-92.

Madoz, L. V., M. Giuliodori, M. Jaureguiberry, J. Plöntzke, M. Drillich, and R. De la Sota. 2013. The relationship between endometrial cytology during estrous cycle and cutoff points for the diagnosis of subclinical endometritis in grazing dairy cows. J. Dairy Sci. 96:4333-4339. 
McDougall, S., R. Macaulay, and C. Compton. 2007. Association between endometritis diagnosis using a novel intravaginal device and reproductive performance in dairy cattle. Anim. Reprod. Sci. 99:9-23.

Miller, R. H., H. Norman, M. Kuhn, J. Clay, and J. Hutchison. 2007. Voluntary waiting period and adoption of synchronized breeding in dairy herd improvement herds. J. Dairy Sci. 90:1594-1606.

Moreira, F., C. Orlandi, C. A. Risco, R. Mattos, F. Lopes, and W. W. Thatcher. 2001. Effects of presynchronization and bovine somatotropin on pregnancy rates to a timed artificial insemination protocol in lactating dairy cows. J. Dairy Sci. 84:1646-1659.

Pinedo, P. J., A. De Vries, and D. Webb. 2010. Dynamics of culling risk with disposal codes reported by Dairy Herd Improvement dairy herds. J. Dairy Sci. 93:2250-2261.

Pursley, J. R., M. R. Kosorok, and M. C. Wiltbank. 1997. Reproductive management of lactating dairy cows using synchronization of ovulation. J. Dairy Sci. 80:301-306.

Rajala-Schultz, P. J., and Y. Gröhn. 1999. Culling of dairy cows. Part III. Effects of diseases, pregnancy status and milk yield on culling in Finnish Ayrshire cows. Prev. Vet. Med. 41:295-309.

Ribeiro, E. S., G. Gomes, L. F. Greco, R. L. A. Cerri, A. Vieira-Neto, P. L. J. Monteiro, F. S. Lima, R. S. Bisinotto, W. W. Thatcher, and J. E. P. Santos. 2016. Carryover effect of postpartum inflammatory diseases on developmental biology and fertility in lactating dairy cows. J. Dairy Sci. 99:2201-2220.

Santos, J. E. P., W. W. Thatcher, R. C. Chebel, R. L. A. Cerri, and K. N. Galvão. 2004. The effect of embryonic death rates in cattle on the efficacy of estrus synchronization programs. Anim. Reprod. Sci. 82-83:513-535.

Santos, V. G., P. D. Carvalho, C. Maia, B. Carneiro, A. Valenza, and P. M. Fricke. 2017. Fertility of lactating Holstein cows submitted to a Double-Ovsynch protocol and timed artificial insemination versus artificial insemination after synchronization of estrus at a similar day in milk range. J. Dairy Sci. 100:8507-8517. https://doi .org/10.3168/jds.2017-13210. In press.

Scott, B. D. 2016. Incorporation of dairy farm survey data and epidemiological patterns for agent-based simulation modeling of dairy herd dynamics. MS Thesis. Department of Animal Science, Cornell University, Ithaca, NY.

Sheldon, I. M., J. Cronin, L. Goetze, G. Donofrio, and H.-J. Schuberth. 2009. Defining postpartum uterine disease and the mechanisms of infection and immunity in the female reproductive tract in cattle. Biol. Reprod. 81:1025-1032.

Souza, A. H., H. Ayres, R. Ferreira, and M. Wiltbank. 2008. A new presynchronization system (Double-Ovsynch) increases fertility at first postpartum timed AI in lactating dairy cows. Theriogenology $70: 208-215$.

Souza, A. H., A. Gümen, E. Silva, A. Cunha, J. Guenther, C. Peto, D. Caraviello, and M. Wiltbank. 2007. Supplementation with estradiol-17 $\beta$ before the last gonadotropin-releasing hormone injection of the Ovsynch protocol in lactating dairy cows. J. Dairy Sci. 90:4623-4634.

Stangaferro, M. L., R. Wijma, M. Masello, M. J. Thomas, and J. O. Giordano. 2018. Extending the duration of the voluntary waiting period from 60 to 88 days in cows that received timed AI after the Double-Ovsynch protocol affected the reproductive performance, herd exit dynamics, and lactation performance of dairy cows. J. Dairy Sci. 101:717-736.

Stevenson, J. S., S. L. Pulley, and H. I. Mellieon. 2012. Prostaglandin $\mathrm{F} 2 \alpha$ and gonadotropin-releasing hormone administration improve progesterone status, luteal number, and proportion of ovular and anovular dairy cows with corpora lutea before a timed artificial insemination program. J. Dairy Sci. 95:1831-1844.

Tenhagen, B.-A., C. Vogel, M. Drillich, G. Thiele, and W. Heuwieser. 2003. Influence of stage of lactation and milk production on conception rates after timed artificial insemination following Ovsynch. Theriogenology 60:1527-1537.

Vieira-Neto, A., R. O. Gilbert, W. R. Butler, J. E. Santos, E. S. Ribeiro, M. M. Vercouteren, R. G. Bruno, J. H. Bittar, and K. N. Galvão. 2014. Individual and combined effects of anovulation and cytological endometritis on the reproductive performance of dairy cows. J. Dairy Sci. 97:5415-5425.

Wiltbank, M. C., G. M. Baez, F. Cochrane, R. V. Barletta, C. R Trayford, and R. T. Joseph. 2015. Effect of a second treatment with prostaglandin F $2 \alpha$ during the Ovsynch protocol on luteolysis and pregnancy in dairy cows. J. Dairy Sci. 98:8644-8654.

Wiltbank, M. C., and J. R. Pursley. 2014. The cow as an induced ovulator: Timed AI after synchronization of ovulation. Theriogenology $81: 170-185$ 